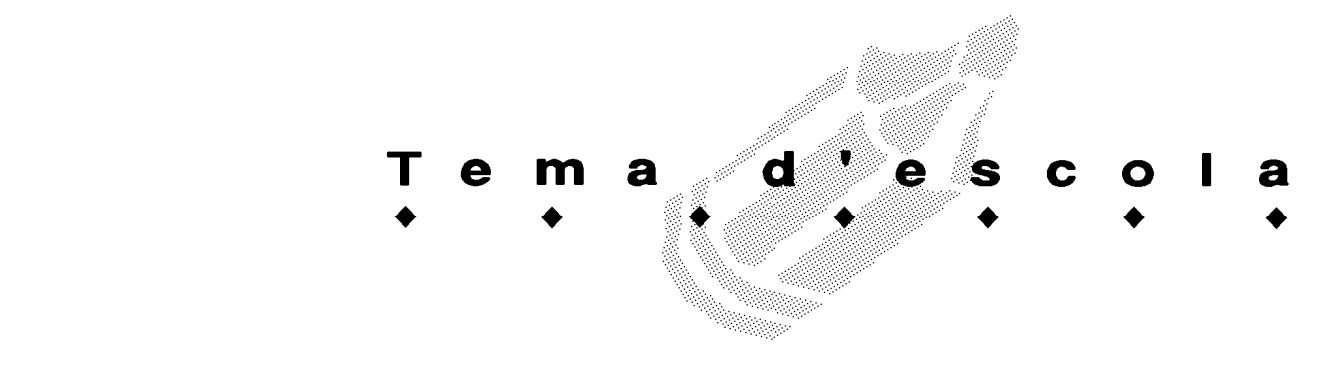

\title{
LES DIDÀCTIQUES DE LES DISCIPLINES CURRICULARS EN LA FORMACIÓ D'ENSENYANTS
}

\author{
Luisa Girondo Pérez. Àrea de Didàctica de la Matemàtica. URV. \\ Agustí Salvat Altés. Àrea de Didàctica de les Ciències Experimentals. URV. \\ Antoni Gavaldà Torrents i Antoni Santisteban Fernández. Àrea de Didàctica de les Ciències Socials. URV. \\ Albert Macaya Ruiz. Àrea de Didàctica de l'Expressió Plàstica. URV.
}

\section{Introducció}

Com molt bé es recull en l'aportació del professor Zabalza (2001) en el recent congrés sobre didàctiques específiques, celebrat a Granada els dies 1, 2 i 3 de febrer d'enguany, les disciplines són conjunts de coneixements formalitzats i especialitzats que tenen simultàniament dues funcions: a) actuar com a contenidor -o de suport- dels coneixements específics del camp i, b) ser una estructura generadora de nous coneixements.

Si de cada disciplina accentuem l'aspecte de contenidor de coneixements, enfocarem prioritàriament el conjunt de conceptes, idees i informacions que aquesta disciplina ens dóna d'algun aspecte de la realitat. Ens estarem preocupant per un coneixement fet, organitzat $i$ disponible en un llibre o en qualsevol altre mitjà contenidor d'informació.

Si accentuem la característica que cada disciplina és una estructura generadora de coneixements, estarem prioritzant la capacitat que cada disciplina té d'utilitzar els seus instruments intel-lectuals, conceptes, procediments, estratègies... per generar coneixement nou -si es treballa en el límit d'investigació punta-, o simplement coneixement -si aquesta idea és al servei de l'aprenentatge de cada individu.

\section{Caracterísitiques de les didàctiques específiques}

Però, donada la problemàtica particular que ens ocupa -la de l'educació de les noves generacions- cal que ens mirem les diferents disciplines, no des del seu interior, sinó al servei de la formació dels individus. Això ens porta, doncs, a la consideració que cada disciplina que compon el currículum escolar és un recurs per a la formació dels alumnes.

Per potenciar aquest aspecte formador de la disciplina cal prioritzar justament els aspectes de generació de coneixement que cada una dóna, i no conformar-se amb els aspectes descriptius de cadascuna. Fent una citació literal (op. cit.): "La riqueza principal de las disciplinas no reside tanto en las informaciones que suministran cuanto en los recursos operativos que ayudan a construir".

Wheler (1976) apunta de manera clara que cada disciplina no es diferencia només en la temàtica que estudia, sinó en la manera que té d'estudiar-la: "Las disciplinas hacen unas aportaciones únicas para el aprendizaje no sólo en cuanto a la información de hechos, sinó en la manera específica de pensar que emplean, en el uso de un lenguaje lógico especial, en el nivel de abstracción y en su consiguiente impacto mental. Cada disciplina difiere en las exigencias lógicas que hace al alumno, de manera que no todos los procesos lógicos pueden enseñarse igualmente bien en todas las materias. Se diferencian no sólo en los hechos, sino en la forma de tratar los hechos e ideas, en el equilibrio entre deducción e inducción y en la medida en que las generalizaciones son dignas de confianza y son universales. El proceso lógico de pensamiento no tiene exactamente el mismo significado en todos los contextos".

Tradicionalment no s'ha tingut aquesta visió de la particularitat formativa de cada disciplina, i per tant s'ha estat poc respectuós amb la forma en què cadascuna s'ha tractat a nivell escolar. Es portaven a l'escola els aspectes informatius, i per tant, en termes de didàctica, n'hi havia prou amb un aspecte general -el "d'aprendre a ensenyar"-, ja que variaven les informacions a transmetre des de cadascuna, però la concepció de "coneixements acabats que cal transmetre" era semblant a totes les matèries.

La despreocupació pels processos mitjançant els quals s'assimilen els continguts específics porta a no valorar l'efecte cognitiu en el desenvolupament intel-lectual de qui aprèn, situació dolenta des del punt de vista del desenvolupament cognitiu de l'estudiant i també des del punt de vista de l'assoliment d'uns aprenentatges funcionals i significatius.

D'un temps ençà, es pretén que la situació canviï. Les investigacions sobre l'ensenyament-aprenentatge aporten models explicatius cada vegada més coherents envers l'adquisició de coneixements conceptuals i procedimentals, sobre el pensament estratègic... i els nous 


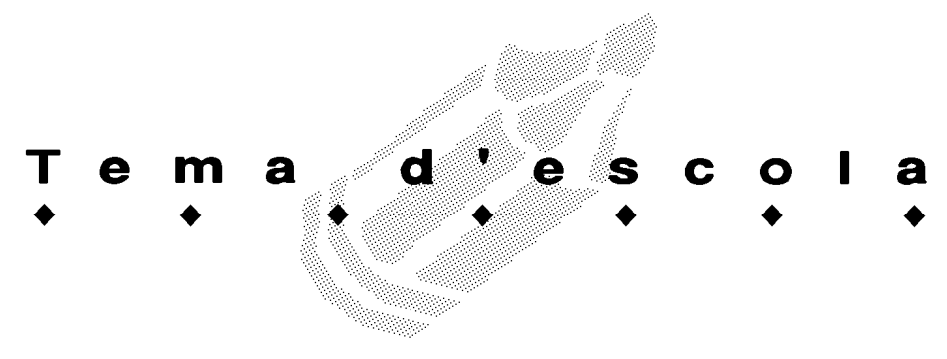

dissenys curriculars s'estructuren al voltant de la comprensió de qui aprèn i de la funcionalitat dels aprenentatges.

Aquesta nova concepció dóna importancia-almenys en el pla teòric- a la didàctica de cada disciplina curricular, perquè, com ja s'ha dit, no es tracta de dotar els individus amb coneixements elaborats -informacions a rebre- sinó que es tracta d'ajudar-los a construir el seu esquema intel-lectual de forma que els serveixi per explicar-se i interactuar en la societat que els toca viure. I com ja s'ha dit abans, cada disciplina aporta peculiaritats diferents en aquesta construcció intel-lectual.

\section{Situació actual de les didàctiques específiques}

A nivell legal s'ha reconegut la diferenciació suara explicada $\mathrm{i}$ ja fa uns quinze anys que a la universitat espanyola s'han creat les diferents àrees de Didàctica de... (Didàctica de la Llengua, Didàctica de la Matemàtica, Didàctica de l'Expressió Plàstica...). És a dir, les didàctiques de les diferents disciplines que se seleccionen en els currícula no universitaris. És de suposar que això és així, ja que és en aquests nivells quan han de primar els aspectes formatius per damunt dels informatius. Tot i que es podria analitzar què passa amb la informació i la formació a l'ensenyament superior, no es tractarà aquesta qüestió.

Com a professors universitaris d'aquestes àrees, ens plantegem sovint el nostre objectiu professional, tant pel que fa als aspectes de docència de l'àrea com pels aspectes d'investigació o contribució a la creació de nou coneixement. En el present informe es vol donar una visió de l'estat de la qüestió des de cada una de les àrees en particular.

Abans que cada àrea contesti particularment, s'especificaran alguns aspectes comuns que condicionen, també, la tasca professional a cada una de les universitats i que porta, necessàriament, a actuacions i produccions diferents.

Totes les àrees de Didàctica de... són camps de coneixement força joves a l'Estat espanyol-com ja s'ha dit abans-, a les quals s'han adscrit, quasi exclusivament, professors del camp disciplinari tradicional o disciplina afí (llicenciats en Física, a la Didàctica de la Matemàtica; Geografia, a la Didàctica de les Ciències Socials...). La immensa majoria d'aquests professors impartien docència a l'antic ensenyament de formació de professorat d'EGB, que, com és ben sabut, era l'única etapa obligatòria del sistema educatiu per a aquells estudiants que en el seu futur professional volguessin dedicar-se a la docència a l'ensenyament obligatori.

En general aquests ensenyaments, tot i que tenien rang de diplomatures universitàries, estaven adscrits a les denominades Escoles de Magisteri -centres amb un clar component de formació encarat a una titulació docent. És a dir, a més de la visió psico-sòcio-pedagògica, hi havia un component important de la didàctica de les disciplines curriculars.

A partir de la Llei de Reforma Universitària, que ha suposat la creació de les àrees abans esmentades, desapareixen en moltes universitats -per altres aspectes de la llei-, el centre específic de titulació docent i es creen les denominades Facultats d'Educació. Aquestes facultats neixen de la unió de diversos ensenyaments, entre ells el de titulació de Mestre. Cal dir que a les universitats petites, com la nostra, ni tan sols existeix la Facultat d'Educació, sinó que es creà la Facultat d'Educació i Psicologia, amb la qual cosa l'aspecte de titulació docent encara és més eteri.

Aquesta nova estructura de funcionament, en principi positiva pel que fa al reconeixement d'estatus universitari d'unes determinades àrees $i$, fins $i$ tot, dels estudis de mestre, també genera certs conflictes, per la pèrdua d'influència en el currículum de les titulacions docents, de les àrees relacionades amb les disciplines escolars -en aquest cas, les matèries responsabilitat de les àrees de Didàctica de...-; pèrdua que afavorí les àrees de la vessant psicopedagògica. Aquestes últimes aprofiten el fet d'estar en millor posició -al ser tradicionalment consultades en qüestions educatives- $i$ estar en condicions de majoria en els nous centres docents, per imposar els seus interessos en les places docents, creixement de l'àrea, etc., i donar a la titulació docent de mestre un caràcter genèric de "Ciències de l'Educació" i minimitzant el paper de les Didàctiques específiques.

Caldria dir que aquesta circumstància pot, fins i tot, estar generada per una interpretació equívoca al voltant del que significa la didàctica de cada displina. Com s'ha vist abans, no concebem la didàctica de la matemàtica separada de la matemàtica, per posar un exemple; és precisament la necessitat de formar els alumnes en les maneres de pensar, en la utilització del llenguatge matemàtic i en l'adquisició comprensiva dels conceptes i procediments que utilitza la disciplina el que fa que, amb el nom genèric de Didàctica de la Matemàtica, es presenti una mirada de la matemàtica amb finalitat educativa; però matemàtica, no altra cosa! En els països anglosaxons la denominació emprada és la d'Educació Matemàtica. De fet el nom de Didàctica de... tampoc ajuda gens a clarificar la situació. Alguns, fins i tot, pensaven que corresponia a aquell trimestre del curs que, des de la didàctica general, es dedicava a parlar de les disciplines escolars!

Si a les circumstàncies abans esmentades s'hi afegeix la nova formació de mestres especialistes en 


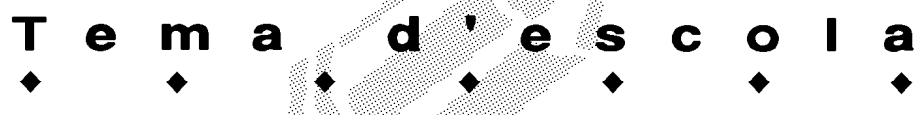

algunes àrees, és fàcil veure la notable manca de temps dedicada a la formació dels futurs mestres en les didàctiques de les disciplines escolars. Per tots és coneguda l'etèria -per no usar un altre qualificatiu- formació professional dels docents de secundària.

En aquest estat general de coses, a partir de les següents preguntes, i respostes us podeu fer una idea del funcionament, problemes i expectatives del professorat d'algunes de les àrees de coneixement de la URV.

\section{Al vostre parer ha suposat un encert la creació de l'àrea Didàctica de...?}

DidÀCTICA DE LA MATEMÀTICA. La resposta, en aquest cas, és rotundament sí. La matemàtica ha estat un contingut curricular indiscutible en tots els currícula antics i moderns i a tot el món. Ningú discuteix el valor formatiu ni el valor instrumental d'aquesta disciplina.

Però també és cert que els conceptes i procediments que utiliza la matemàtica no són fàcilment aprehensibles per tothom, i doncs, tant per la importancia que té aquesta manera de pensar en la formació intel-lectual de l'individiu com per les dificultats que apareixen, s'ha investigat molt sobre qüestions que ara es recullen en el camp de la Didàctica de la Matemàtica. En el nostre país són més recents, però tant en altres països d'Europa com d'Amèrica s'havien generat grans quantitats de coneixements propis de l'àrea que justifiquen sobradament la dedicació universitària específica a aquest camp.

DidÀCTICA DE LES Cİ̀nCIES EXPERIMENTALS. És evident que la resposte és sí. Les ciències experimentals (la física, química, biologia i geologia, del pla del 72) tenen un paper important tant en l'aspecte informatiu com en el formatiu dels individus com a elements de la societat que els toca viure. Altra cosa és que els conceptes, procediments i tècniques usades en aquesta matèria siguin fàcilment assimilables per tothom. De fet, aquestes dificultats han originat una infinitud d'investigacions didàctiques, especialment als països anglosaxons. A l'Estat espanyol la qüestió és més recent, però l'elevada quantitat de coneixement generat sobre l'àrea -val a dir que la revista d'investigació i experiències didàctiques «Enseñanza de las Ciencias», veié la llum l'any 1983justifiquen, amb escreix, la creació de l'àrea.

DidÀcticA de les CIĖncies Socials. Sí, sens dubte, la seva concreció com a àrea va paralel.la a la professionalització de la feina de fer de mestre i a la concepció universitària dels estudis de magisteri. És un encert, sempre i quan les finalitats de l'ensenyament de les ciències socials, sempre en discussió, facin referència $a$ l'educació democràtica, a la intervenció social o a la reconstrucció del coneixement o a la maduració de les persones com a protagonistes de la història i que formen part de la societat. Quan no són aquestes les finalitats, la Didàctica de les Ciències Socials es converteix en aquella "metodologia" o "instrument" per aprendre millor, no en un camp científic on es pugui investigar i avançar per millorar l'educació social.

DidÀctica de L'Expressió Plàstıca. Òbviament. La didàctica de l'expressió plàstica té com a objectiu un món diferent del de les arts visuals. Com en totes les didàctiques específiques, cal plantejar la problemàtica pròpia de l'àrea quant a la transmissió de continguts, la seva seqüenciació, l'avaluació. Per a plantejar un àrea curricular no és suficient posseir una sèrie de coneixements psicopedagògics de caràcter general. Cal aprendre a pensar en els termes de disciplines específiques; aproximar-nos a la seva estructura conceptual. Aquesta idea no està renyida amb plantejaments interdisciplinaris o amb formulacions transversals del currículum.

\section{Quant professorat hi ha i en quines línies d'investi- gació es treballa?}

DidÀctica dE LA MATEMÀticA. En tot l'Estat hi ha uns 230 professors i professores adscrits a l'àrea. Cinc d'ells són catedràtics d'Universitat. Algunes universitats tenen departament específic, amb el que això suposa de cursos de doctorat, tesis, i en general, estructura investigadora en el camp específic. La investigació està fortament decantada cap a aspectes cognitius de temes concrets. D'altres tenen poc professorat adscrit a l'àrea, i per tant l'ubiquen en departaments de continguts de la mateixa disciplina o en d'altres casos agrupa les àrees de Didàctica de... en departaments. Quan això succeeix, s'han fet esforços per fer tesis, però no és fàcil tenir continuïtat investigadora en el camp específic. El professorat investiga en línies més interdisciplinàries, com pot ser formació de professorat, temes tranversals del currículum, etc.

DidÀctica de les Ciències Experimentals. A tot l'Estat espanyol i ha uns 225 professors adscrits a l'àrea. 10 d'ells són catedràtics d'Universitat i 90 són titulars d'Universitat o catedràtics d'Escola Universitària. La majoria de professors, uns 125, són titulars d'Escola Universitària. Algunes universitats tenen departament propi (cas de Múrcia i de Granada, per citar-ne algunes), mentre que d'altres han format departament amb àrees de coneixement pròximes (com la universitat Autònoma de Barcelona, que configura el departament amb l'àrea de Didàctica de la Matemàtica). A la nostra universitat no s'ha seguit cap dels dos models anteriors. Al professorat de l'àrea l'han adscrit, per "decret", a un departament que no té res a veure amb la professió docent, llevat de la pròpia docència universitària. Com a curiositat pot destacar-se el fet que la universitat de Lleida, petita i de 


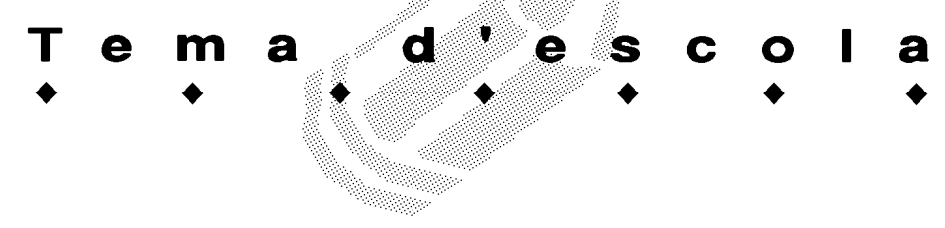

recent creació, com la nostra, té l'àrea de Didàctica de les Ciències Experimentals amb el seu catedràtic d'Universitat.

Pel que fa a la investigació de l'àrea, se segueix el model anglosaxó i la majoria de treballs se centren en els aspectes cognitius i conceptuals propis de l'àrea -això es dóna, especialment, als camps de la física i de la química. També hi ha professorat de l'àrea que investiga sobre temes de caire interdisciplinari.

DidÀcticA de les CiènCIES Socials. A l'Estat hi ha uns 180 professors i professores, la majoria titulars d'Escola Universitària (uns 100). Hi ha 5 catedràtics d'Universitat i els titulars universitaris augmenten en segons quines universitats. Els departaments específics de Didàctica de les Ciències Socials són majoritaris, sobretot en les universitats més grans, encara que també trobem departaments de didàctiques específiques, amb la unió d'aquestes àrees, en universitats petites com Girona 0 Lleida. En altres universitats l'àrea de Didàctica de les Ciències Socials està unida en el departament a l'àrea de Didàctica de la Llengua i la Literatura (cas de la UAB) o a l'àrea de Didàctica de les Ciències Experimentals (cas de València). La situació de la nostra universitat comença a estar a la cua en el procés lògic de normalització i avenç del procés de construcció científica de l'àrea. La nostra àrea està en un departament de la Facultat de Lletres que no té res a veure amb l'ensenyament (Història i Geografia). Les investigacions o les tesis han estat nombroses en els últims 10 anys, encara que no ha estat fins fa 5 anys que les temàtiques han començat a centrar el camp de coneixement de la Didàctica de les Ciències Socials, amb dèficits molt importants. Destaca, per exemple, la investigació, en la qual vam poder participar, sobre els conceptes clau de ciències socials i la seva aplicació curricular, subvencionada pel MEC i on participaven quatre universitats catalanes i altres de la resta de l'Estat espanyol.
DidÀctica de L'Expressió PlÀstica. A tot l'Estat hi ha uns 180 professors adscrits a l'àrea. La majoria són titulars d'Escola Universitària (130). Hi ha 5 catedràtics d'Universitat.

Des de fa uns anys, el tema de l'apreciació estètica ha estat guanyant terreny. La influència d'estudis recents d'orientació cognitiva sobre l'evolució de la comprensió de l'art en nens i adolescents ha obert nombroses vies d'investigació. Més recentment, sota la influència dels "cultural studies" anglosaxons, hi ha investigacions que relacionen l'educació artística amb l'univers de les imatges en general, com a vehicle de trets d'identitat, modes de coneixement, ideologies, etc.

\section{Quines orientacions tenen força des de cada àrea de Didàctica de...? ¿Com penses que ha de ser el treball propi en el present i en el futur?}

DidÀctICA DE LA MATEMÀTICA. Entenent que l'apartat d'investigació s'ha contestat anteriorment, m'estendré una mica en l'apartat de docència. Tot i que l'àrea consta d'una gran quantitat de coneixements i procediments propis, lògicament derivats de la mateixa disciplina i amb aportacions rebudes des d'altres àrees com la psicologia, la pedagogia, la filosofia, la sociologia, etc. quan s'incorpora al currículum de la formació de mestres es fa des d'una perspectiva tan general com "Matemàtiques i la seva Didàctica" que es fa difícil per a un no expert saber el que es vol dir. Jo entenc que els dissenyadors del currículum, posats a estalviar hores de les matèries curriculars -segurament amb motivacions difícils d'explicitar i amb la justificació que la matèria curricular ha estat objecte d'estudi en els nivells no universitaris- han optat per aquesta formulació marc, deixant que cada universitat acomodi la formació a les seves possibilitats. I com que les possibilitats són força diverses, naturalment la formació també ho és. En algunes universitats hi ha una vintena de professors de

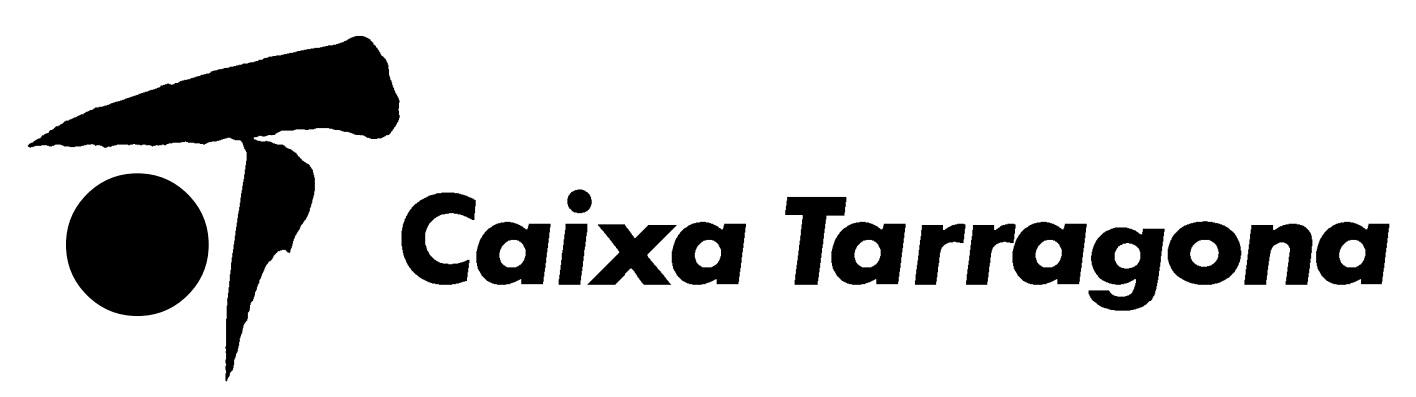




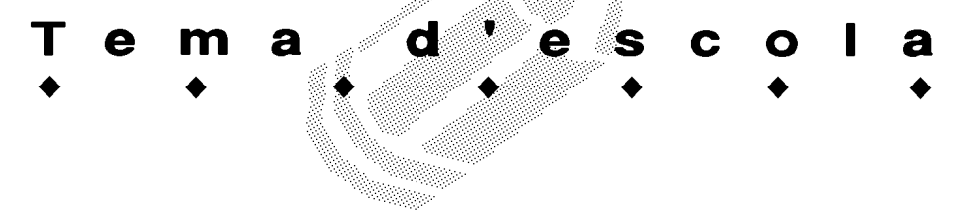

l'àrea... i en els casos límit com la nostra, només hi ha un professor. No cal dir l'especificitat d'assignatures, l'adequació a especialitats i nivells, els treballs de recerca... que es poden generar en un cas o l'altre.

DidÀcticA de les CIÈnCIES Experimentals. El nostre cas és especial dins les àrees de didàctiques específiques. Cap àrea s'ha format per la unió de quatre tipus de professor amb formació acadèmica força diferent: física, química, biologia i geologia. Això, a banda de la complexitat de funcionament que genera dins l'àrea, sembla que tampoc no s'ha tingut gaire en compte quan l'àrea s'incorpora al currículum de l'ensenyament de mestre. Amb títols tan genèrics com "Ciències experimentals i la seva didàctica" o "Medi natural i la seva didàctica" es pretén liquidar el tema. És evident que per a un no expert això de les "ciències" -naturals, per descomptat!- tot és el mateix. Així, la nostra universitat i la facultat que té cura del pla d'estudis de l'ensenyament de mestres no han tingut en compte l'especificitat de cada especialitat a l'hora de fer el pla d'estudis, malgrat que l'àrea té professorat suficient per contemplar aquesta especificitat.

DidÀCTICA DE LES CIÈnCIES SocIALS. A l'àrea existeixen diferents tendències, encara que podem distingir-ne clarament dues: una que se centra en l'ensenyament de la geografia i la història i en els seus continguts científicodisciplinaris. I una altra, que posa l'èmfasi en la formació crítica de la ciutadania, analitzant les aportacions que cada ciència social pot fer a aquesta formació.

DidÀcticA de L'Expressió PlÀsticA. L'orientació majoritària és, probablement, la que se centra en la noció de llenguatge plàstic. L'expressió plàstica es contempla com un llenguatge amb uns elements formals (traç, color, forma, volum...) en els quals s'ha d'introduir l'alumne. Aquesta noció va asociada, en la pràctica, a tota una tradició expressionista molt arrelada a l'àrea. A més de la preocupació per l'apreciació de l'art i la formació del criteri estètic a què ja hem a l-ludit, hi ha també una altra orientació que guanya terreny sota l'epígraf "cultura visual": es tractaria d'anar més enllà dels plantejaments expressionistes a l'ús i considerar les múltiples dimensions de la imatge en el nostre entorn cultural. No sols la seva dimensió estètica o expressiva, sinó també l'antropològica, social, ideològica...

\section{Amb quines limitacions es compta en els nous pro- grames de formació inicial de mestres per aconseguir "bons mestres"?}

DidÀctICA DE LA MATEMÀTICA. Tot i que matèries pròpies de l'àrea de Didàctica de les Matemàtiques s'han incorporat amb èxit en algunes universitats a la llicenciatura en matemàtiques i/o a la llicenciatura en psicopedagia, és cert que la major part de la docència cau en la formació inicial de mestres.

En aquest ensenyament només es pot parlar d'una certa formació en les especialitats d'Educació Infantil i d'Educació Primària; en totes les altres o és nul·la, com el cas d'Educació Especial, o pràcticament nul-la per la seva escasa presència (només tres hores setmanals durant un quadrimestre, inferior al $3 \%$ del pes curricular).

A més de l'exigüitat caldria citar com a dificultat el poc nivell de competència en matemàtica elemental de gran part de l'alumnat que arriba a aquests estudis, segurament fruit d'una història escolar informativa de la disciplina. El resultat és que no els serveixen de gaire cosa pràctiques rutinàries mal apreses i les nocions estereotipades que tenen sembla que estorben més que ajuden a un plantejament racional de la matèria.

DidÀCTICA DE LES CIĖNCIES EXPERIMENTALS. Els programes de formació inicial dels mestres van de mal en pitjor. Cada vegada que hi ha retallada dels plans d'estudi, ja se sap que a les àrees de didàctiques específiques els tocarà el rebre. Potser només es pot parlar d'una certa formació a l'especialitat d'Educació Primària (3 assignatures de 4,5 crèdits). A la resta d'especialitats només hi ha una assignatura de 3 hores setmanals durant un quadrimestre, que en algun cas fins i tot es comparteix amb l'àrea de Didàctica de les Ciències Socials. Per altra part, hi ha una dificultat afegida al nostre treball, ja que, a conseqüència de la formació "científica" rebuda pels alumnes durant l'ensenyament primari i secundari, es fa necessari un treball previ de deconstrucció i construcció del coneixement científic, a la vegada que s'ha d'aprendre a fer de mestre per ensenyar ciències experimentals des d'una perspectiva lògica.

DidÀctica de les Ciències Socials. Destaquem quatre dificultats. La primera té a veure amb la distinta incidència de l'àrea en les especialitats, on destaca Educació Primària, amb tres assignatures de 4,5 crèdits, una a cada curs; però la resta té una docència de 4,5 crèdits en els tres cursos. La segona és la dificultat de l'àrea per disposar d'unes pràctiques concretes o tenir un espai propi dins de les pràctiques generals, de tal manera que ens movem dins la teoria sense aplicació real i sense poder reproduir, només a través de vídeos i estudi de casos, l'ambient real de l'aula. La tercera afecta també el coneixement pràctic, donada la dificultat de disposar de materials curriculars propis per a l'experimentació, encara que aquest aspecte es pot solucionar amb el futur laboratori de Didàctica de les Ciències Socials. Quart i ultim, destaquem la dificultat en el nostre treball com a conseqüència de l'educació rebuda en els estudis anteriors dels mateixos estudiants, les seves concep- 


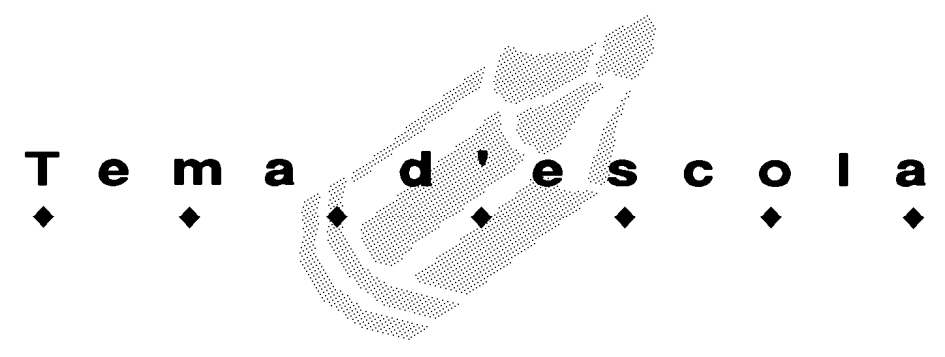

cions, procediments de treball i actituds i valors socials, que fa necessari un treball previ de deconstrucció i reconstrucció del coneixement social, a la vegada que es defineix la funció de fer de mestre per ensenyar ciències socials des d'una perspectiva crítica.

DidÀctica de L'Expressió Plàstica. Pel que fa a la nostra àrea, la formació inicial del mestre és ínfima. Una formació amb un mínim de credibilitat passaria per la creació de mestres especialistes en Educació Visual i Plàstica. Ben al contrari, en aquests moments la presència de l'àrea en el currículum de formació de mestres és testimonial o nul.la (com en el cas del mestre d'educació musical; matèria que, paradoxalment, comparteix amb expressió plàstica el calaix comú d'educació artística al currículum de primària). L'explicitació de les limitacions per aconseguir "bons mestres" de plàstica -com diu l'enunciat de la pregunta- en el context actual desbordaria els límits d'aquest article.

\section{Com es participa des de les diferents Didàctiques de... en la formació inicial del professorat d'altres nivells?}

DiDÀCTICA DE LA MatemÀtıCA. Evidentment és un camp propi de treball. Algunes universitats han preparat el nou curs de capacitació per a l'ensenyament secundari que preveu la llei, però no s'ha generalitzat la seva implantació.

DidÀctica de les Ciències Experimentals. De fet, l'àrea, com a tal, no participa en la formació inicial del professorat d'altres nivells. Una altra qüestió és que el professorat de l'àrea, a títol personal, faci cursos organitzats per l'ICE. Per altra part, caldria que la formació en didàctiques específiques del professorat de secundària la fessin les àrees de didàctiques específiques i no altres àrees, com actualment succeeix. Però ja veurem què passa amb el disseny del nou Curs de Qualificació Pedagògica.

DidÀCtICA de les CiènCIes Socials. La formació del professorat de secundària d'història, geografia, etc., és un tema pendent a la nostra universitat, ja que ni tan sols la realitza l'àrea de Didàctica de les Ciències Socials. En el futur cal treballar decididament per dissenyar el nou Curs de Qualificació Pedagògica, i no cal dir que les didàctiques hi hauran de tenir un pes fonamental.

DidÀctica de l'Expressió Plàstica. A les facultats de belles arts hi ha hagut, tradicionalment, assignatures de didàctica, en previsió del que seria el camp majoritari de sortida laboral dels futurs llicenciats. També ha existit un CAP específic, i, en el cas de la Universitat de BarceIona, un pla experimental de formació del professorat de secundària en arts visuals, que ha funcionat durant els darrers deu anys.

\section{Quines dificultats hi ha en l'aplicació de la formació permanent de mestres o de professorat d'Educació Secundària?}

DidÀCTICA DE LA MATEMÀTICA. La formació permanent és també un camp de treball interessant. Diverses universitats han ofert cursos de postgrau en didàctica de la geometria, en resolució de problemes... Tenen un cert èxit si l'administració els subvenciona. No tant si s'han de fer a partir dels recursos propis del professorat.

DidÀcticA DE LES CIÈnCIES EXPERIMENTALS. De fet no n'hi hauria d'haver. Però la realitat és ben diversa. ¿Com es pot participar, com a àrees de didàctica, en la formació permanent del professorat de distints nivells si aquestes àrees no tenen departament propi? Mentre la situació sigui aquesta, la responsabilitat de la formació recaurà en altres àrees, menys idònies i específiques, però més fortes administrativament pel fet de tenir departament propi.

DidÀctica de les Ciències Socials. El professorat de secundària és, en general, reticent a la formació didàctica, encara que a través de la formació permanent es poden obrir camins de canvi. La variació de les preconcepcions és una feina molt difícil i que requereix metodologies d'impacte. Malgrat tot, és una feina necessària, en la qual hem tingut una gran experiència en els últims anys, dins i fora de Catalunya. Caldria, en aquests moments, reflexionar sobre les accions realitzades i definir les línies d'actuació necessàries.

DidÀctICA DE L'EXPRESSIÓ PLÀsticA. Existeix l'oferta de cursos dels ICE, que aporten propostes interessants, però de caràcter puntual. Algun ICE compta amb grups de treball actius, que organitzen jornades anuals, com en el cas de la Universitat de Barcelona. Algunes universitats catalanes han proposat cursos de postgrau en educació visual i plàstica per a mestres, o de cultura visual per a professors de secundària. La resposta del professorat ha estat, en alguns casos, tèbia; en especial pel que fa a primària, on la forta despesa econòmica de matrícula d'un curs de postgrau no condueix l'alumne a cap especialització reconeguda.

\section{Referències bibliogràfiques}

WHELER, D. K. El desarrollo del currículum. Edit. Santillana. Madrid. 1976.

ZABALZA, M. A. El sentido de las didàcticas específicas en las ciencias de la educación. Dins a Actas Congreso Nacional de Didàcticas Especificas. Universitat de Granada. Febrer 2001. 